\title{
Mechanism of $\{332\}<113>$ Twinning Formation in Cold-Rolled Ti-Nb-Ta-Zr-O Alloy
}

\author{
Jinhui Sun and Leng Chen * \\ School of Materials Science and Engineering, University of Science and Technology Beijing, \\ Beijing 100083, China; sunjinhui19@163.com \\ * Correspondence: lchen@ustb.edu.cn; Tel.: +86-10-6233-2919 \\ Received: 10 November 2018; Accepted: 13 December 2018; Published: 18 December 2018
}

\begin{abstract}
In this study, the mechanism of $\{332\}<113>$ twinning formation in cold-rolled Ti-35Nb$2 \mathrm{Ta}-3 \mathrm{Zr}-\mathrm{O}(\mathrm{wt} \%)$ alloy was investigated based on the Taylor-Bishop-Hill theory. The experimental data of crystal orientation in the rolling bite zone was obtained via electron back-scattered diffraction (EBSD). The deformation energy of $\{332\}<113>$ twinning in the propagation stage was calculated using data from EBSD in terms of the Hall-Petch-type relation. The calculation results revealed that the mechanism of $\{332\}<113>$ twinning formation in $\beta$-type Ti-35Nb-2Ta-3Zr-O (wt \%) alloy contained two valid models, namely the shear-shuffle model and $\alpha^{\prime \prime}$-assisted twinning model. This can help to clarify the mechanism of $\{332\}<113>$ twinning formation further.
\end{abstract}

Keywords: Ti-35Nb-2Ta-3Zr-O (wt \%) alloy; mechanism of $\{332\}<113>$ twinning formation; deformation energy

\section{Introduction}

Metastable $\beta$-type titanium-niobium (Ti-Nb)-based alloys are widely developed for application in biomedical [1-3] and automobiles [4,5] since the alloys exhibit low Young's modulus (30-40 Gpa) [1,4,6] and an optimal combination of strength (more than $500 \mathrm{MPa}$ roughly) and ductility (more than $15 \%$ ) [6,7]. The $\beta$ phase in Ti-Nb-based alloys corresponds to a body-centered cubic (bcc) structure, and its space group corresponds to Im-3m [8]. The dominant deformation mechanism for $\beta$-type titanium (Ti) alloys corresponds to twinning and/or stress-induced martensitic transformation with decreasing levels of $\beta$ phase stability [9]. Additionally, the common deformation twinning modes in $\beta$-type titanium alloys include $\{112\}<111>$ and $\{332\}<113>$ twins [10-12], and thus the predominant deformation mechanism corresponds to $\{332\}<113>$ twinning formation only for $\beta$-type Ti alloys including Ti-Nb base [13] and Ti-Mo-based alloys at room temperature [14]. The $\{332\}<113>$ twinning exhibits superior mechanical properties such as high elongation percentage (40\% in Ti-Mo alloy) [14] and high strength(yield strength $750 \mathrm{MPa}$ roughly in Ti-Mo alloy) [15]. Specifically, $\{332\}<113>$ twinning was first identified in a Ti-15Mo-6Zr-4Sn (wt \%) $\beta$-type titanium alloy in the 1970s by Blackburn et al. [16]. Subsequently, it was confirmed in various $\beta$-type titanium alloys including Ti-Nb alloys [17]. Recently, extant studies indicated that $\{332\}$ twinning obeys Schmid's law $[18,19]$. However, the mechanism of $\{332\}$ twinning formation is not very clear. There are broadly two types of theories for the mechanism of \{332\} twinning formation, namely shear-shuffle type and $\alpha$ "-assisted type.

Crocker [20] proposed simple shears on successive twinning planes $\{332\}$ along the $<113>$ twinning direction including that in $\{112\}<111>$ twinning, i.e., the shear-shuffle model. However, the magnitude of the shuffle of the model was significantly high and induced energy-related difficulties on planes with small inter-planar spacing. Kawabata et al. [12] corrected the position of the shuffle in order to reduce the magnitude of the shuffle, which was accomplished by $\{332\}<113>$ twinning via the successive slip of $1 / 22<113>$ partial dislocations on pairs neighboring \{332\} planes. Litvinov et al. [21] 
proposed that analogous partial dislocation mechanism was characterized by the gliding of $5 / 22<113>$ partial dislocations on a stack of $\{332\}$ planes without atomic shuffle.

Recently, Lai et al. [22]. proposed that $\{332\}$ twins nucleated within progressively formed $\alpha^{\prime \prime}$ martensite during the deformation in $\beta$ Ti-36Nb-2Ta-3Zr alloy. The $\alpha^{\prime \prime}$ crystal lattice can be derived from the $\beta$ crystal lattice by $\{011\}<011>_{\beta}$ shuffles with a relatively small shuffle amplitude through slight deformation [22,23]. More recently, Chen et al. [24] indicated that the stress-induced $\alpha^{\prime \prime}$ martensite structure remains in the $\{332\}<113>_{\beta}$ twin boundary region and exhibits a gradual transition to the $\beta$ structure with an orientation relationship of $(130)_{\alpha^{\prime \prime}} / /(332)_{\beta}$. They considered that the formation of $\{332\}<113>$ twins in deformed metastable Ti-Nb-based alloys is associated with a reversible $\beta$-to- $\alpha$ " martensitic transformation. Additionally, Shin et al. [3] revealed that $\{332\}<113>$ twinning exhibited a softening effect in the condition when a highly twinned structure is formed, and thus it is assumed that the \{332\} twinning is associated with the $\alpha$ " phase. Zhang et al. [25] reported that $\{332\}<113>_{\beta}$ twinning forms from $\{130\}<310>_{\alpha^{\prime \prime}}$ plastic twins in a full $\alpha^{\prime \prime}$ Ti-Nb alloy by annealing. Tobe et al. [26] proposed that $\{332\}<113>$ twinning can form via the shuffling of adjacent $\{110\}$ planes in $<011>$ directions in theory, and this may be viewed as an extension of the $\alpha^{\prime \prime}$-assisted mode.

Deformation energy is also known as strain energy, and it consists of elastic strain energy and plastic strain energy [27]. Plastic deformation energy is usually applied to investigate material processing [28,29]. Recently, Wang et al. [30] reported twinning variants with maximum deformation energy (also referred to as free path energy) can be activated in titanium alloys. Simultaneously, internal stress led to minimum work in the active variants of twinning while external stress led to maximum work in terms of the Taylor-Bishop-Hill model [31,32]. Recently, Ma et al. [33] predicted the forming limit in DP590 steel sheet forming using deformation energy. Additionally, it was coupled with Zener-Hollomon parameter to generally investigate activated energy [34]. Therefore, deformation energy was used to investigate thermal treatment processing [35]. Furthermore, Kochmann et al. [36] calculated the energy threshold value for twinning in terms of deformation energy.

The rolling bite zone contains information including the stress state and friction [37], and thus it is typically investigated for the rolling process $[38,39]$. The full evolution of microstructure is evaluated by examining the rolling bite zone.

The deformation energy of the $\{332\}<113>$ twinning formation is infrequently discussed, and there is a paucity of studies that examine the propagation of $\{332\}<113>$ twinning of $\beta$-type Ti alloys in the rolling bite zone in detail. The objective of the present study involves clarifying the mechanism of $\{332\}<113>$ twinning formation via the analysis of deformation energy in cold-rolled Ti-35Nb-2Ta-3Zr-O (wt \%) alloy from the rolling bite zone. This investigation attempts to analyze the mechanism of $\{332\}<113>$ twinning formation from deformation energy using Hall-Petch-type relation for the first time.

\section{Materials and Methods}

The ingots of the alloy used in the study exhibited a nominal chemical composition Ti-35Nb$2 \mathrm{Ta}-3 \mathrm{Zr}-\mathrm{O}\left(\mathrm{wt} \%\right.$ ) alloy. They were produced from commercially pure $\mathrm{Ti}, \mathrm{Nb}, \mathrm{Ta}, \mathrm{Zr}, \mathrm{TiO}_{2}$, prepared in a vacuum arc furnace, and the oxygen content was controlled through the addition of $\mathrm{TiO}_{2}$. The oxygen content was determined using an inert gas fusion-infrared absorption method. Subsequently, each alloy ingot was melted several times to ensure compositional homogeneity under high purity argon gas atmosphere, and thus was hot forged and hot caliber rolled at $1473 \mathrm{~K}$ to form plates with a thickness of $5 \mathrm{~mm}$. Subsequently, the plates were homogenized at $1073 \mathrm{~K}$ for $40 \mathrm{~min}$ under high purity argon gas atmosphere and then quenched in water. Solution heat-treated samples (ST) were deformed by cold rolling in a single pass with a thickness reduction of $5 \%$. The rolling operation was stopped, then the cold rolling bite zone was obtained, where was measured. The schematic shape of the sample is shown in Figure 1. Thus, the locations detected by EBSD were near the surface of the plate and were denoted as $1,2,3$, and 4 . 


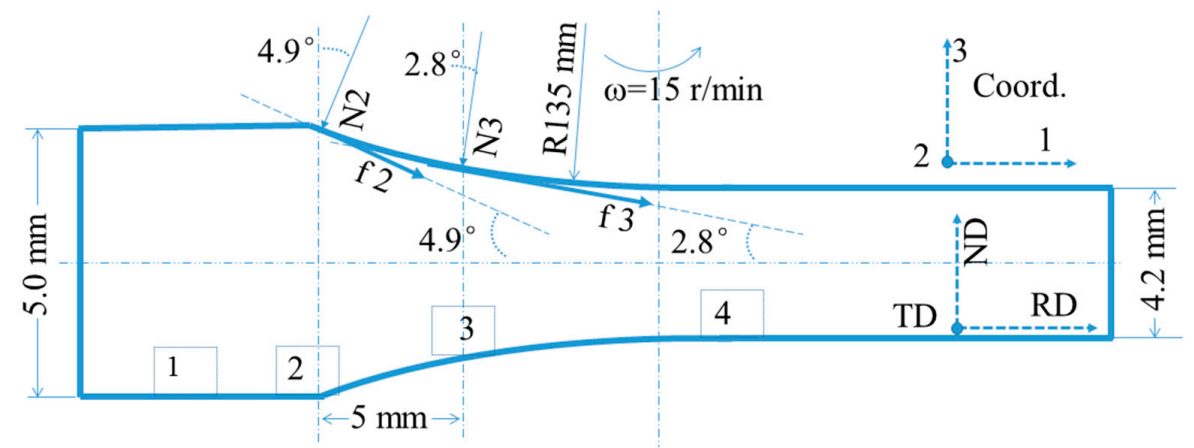

Figure 1. Shape of the sample section and the locations for detection as denoted by numbers 1-4 in the square set correspond to the locations for detection.

The microstructural and crystallographic features of the sample were characterized by electron backscatter diffraction (EBSD) (Oxford Instruments, London, UK.) measurement by using a fieldemission-type scanning electron microscope (FE-SEM) operated at $20 \mathrm{kV}$ and equipped with an HKL orientation imaging microscopy system.

\section{Results}

Figure 2 shows the orientation mappings and coincidence site lattice (CSL) with band contrast of $\{332\}<113>$ twinning corresponding to locations 1, 2, 3, and 4 in Figure 1.
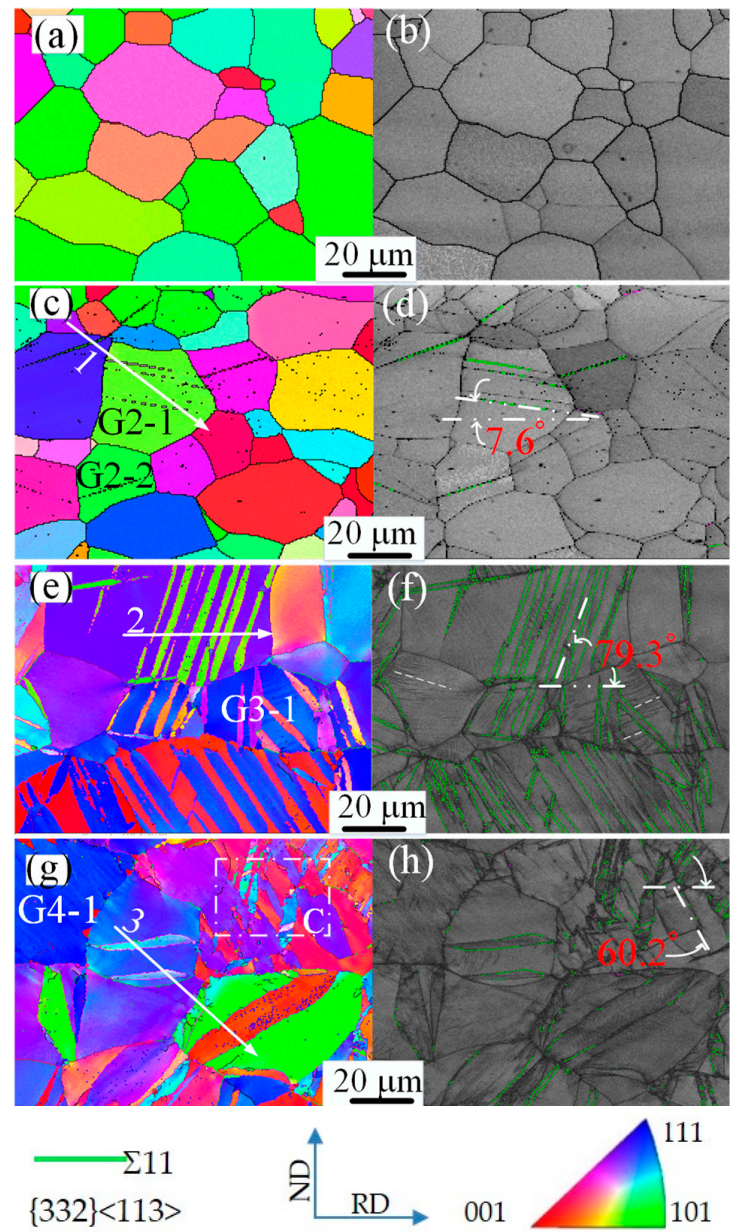

Figure 2. Cont. 

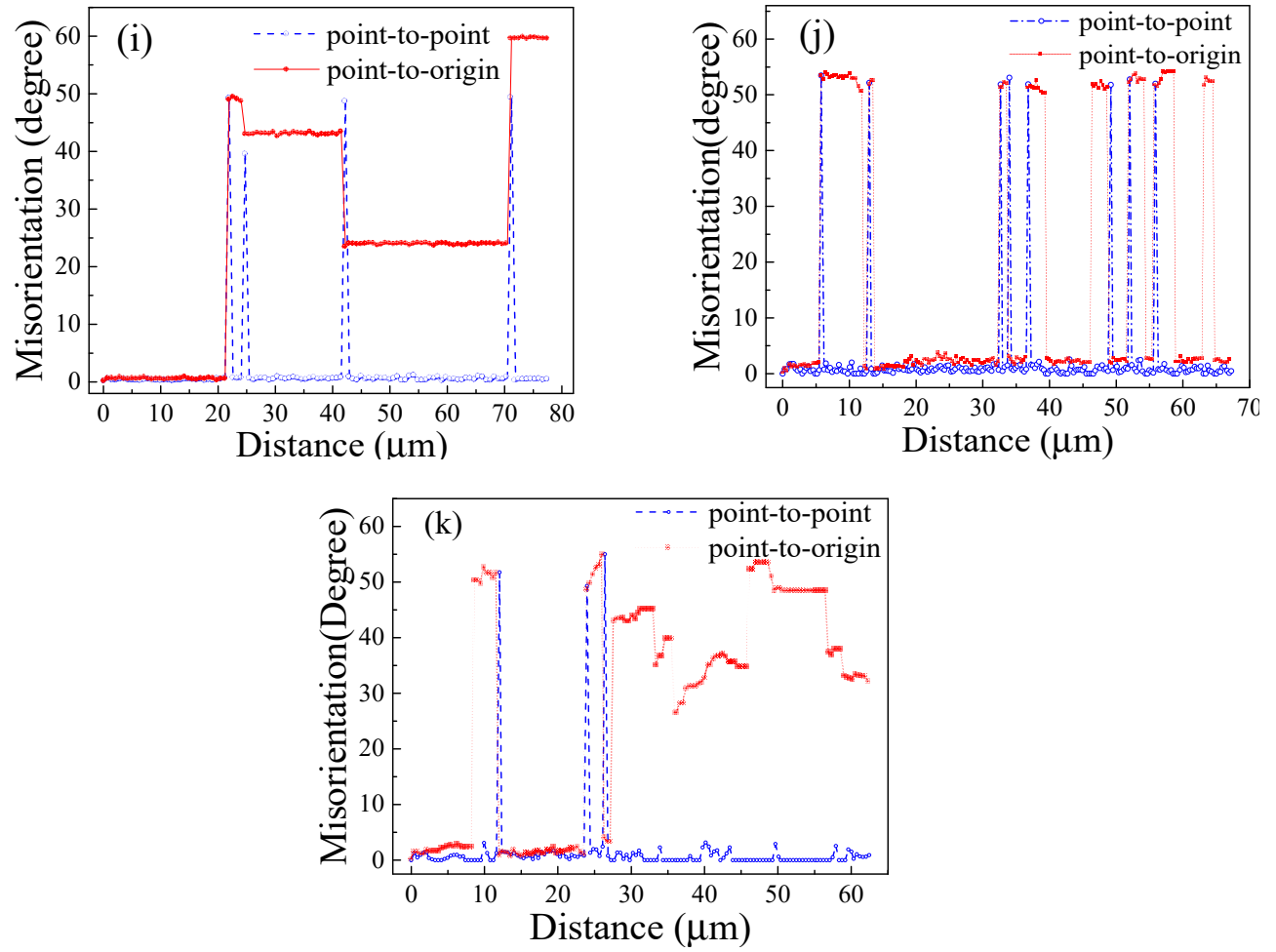

Figure 2. Mappings of orientation and coincidence site lattice corresponding to Figure 1. Among them, (a-b) correspond to location 1, (c-d) correspond to location 2, (e-f) correspond to location 3, and (g-h) correspond to location 4 in Figure 1, (i-k) misorientation profile along the arrow line 1, 2, and 3 in (c), (e) and (g), respectively.

The maps of orientation in Figure 2 was characterized by the evolution of orientation corresponding to locations 1-4 in Figure 1, and it is indicated that the grains are approximately rotated to the $<111>$ orientation from location 2 to 4 in Figure 1. A twinning mode is typically identified by examining misorientation of the related directions or planes in two lattices [40], and the misorientation along the white arrow lines denoted as 1,2, and 3 in Figure $2 \mathrm{i}-\mathrm{k}$ are close to $50.4^{\circ}$, and this characterizes the boundaries of $\{332\}<113>$ twins. Therefore, the green lines inside the grains shown in Figure 2 are characterized as the $\{332\}<113>$ twinning boundaries. Furthermore, the coincidence site lattice (CSL) denoted as $\Sigma 11$ represents the $\{332\}<113>$ twins [11], and thus it is indicated that $\{332\}<113>$ twinning predominates the deformation microstructures. In comparison, it was seen that there were fewer lamellae in Figure 2e than in Figure 2g. The main reason was that Figure $2 \mathrm{~g}$ was closer to the center of the thickness, meanwhile, Figure 2e was closer to the surface of the thickness. Besides, there is ternary $\{332\}<113>$ twinning in the white dot line box and imprints of coalescence of twins (or vanishing of twin boundaries) in the grain marked G4-1 in Figure 2 $g$, while there are no imprints of coalescence of twins and there are only secondary twins in Figure 2e. As shown in Figure 2a,b, prior to the deformation, the as-quenched Ti-35Nb-2Ta-3Zr-O (wt \%) alloy consists of relatively large $\beta$ phase grains with homogeneous equiaxed grain shape and an average grain size of approximately $50 \mathrm{~m}$ while $\{332\}$ twins are not observed. As shown in Figure $2 c, d$, primary $\{332\}$ twins just emerge, and the shape is thin and straight as generated from grain boundaries (GB). The $\{332\}<113>$ twinning forms at the rolling initial stage. It should be noted that the initial $\{332\}<113>$ twinning is observed for the first time in the rolling bite zone. As shown in Figure 2e,f, the thickness of the $\{332\}<113>$ twinning increases and even presents secondary twins while the twinning boundaries (TB) become coarse albeit remaining relatively straight. Additionally, several deformation bands potentially resembled $\{332\}$ twins as denoted by the thin dash in Figure 2f. Min et al. [19] reported similar results for a Ti-Mo alloy. As shown in Figure 2g,h, the CSL of $\Sigma 11$ decreases, and this implies that the coherency TBs 
of $\{332\}$ twinning are missing, a few TBs become bent, and a few $\{332\}$ TBs even turn into entire grain boundaries.

\section{Discussion}

The three typical stages corresponding to the sequence of deformation twinning are nucleation, propagation, and growth [41]. Two stages of deformation twinning evolution strain are shown in Figure 2. The twinning illustrated in Figure $2 \mathrm{c}, \mathrm{d}$ corresponds to the second stage, namely propagation. However, few twins correspond to the growth stage such as the twins inside the grain denoted as G2-1 in Figure 2c. Twinning propagation refers to the process of the twin front moving into the bulk of the grain and eventually encountering a grain boundary or an obstacle, such as another twin, inside the parent crystal [41]. The twinning illustrated in Figure 2e,f, as well as Figure 2g,h, corresponds to the third stage (i.e., growth). The growth process of twinning is subject to a three-step sequence as follows: The formation of twins inside a grain (the thickness of the twin increases), growth (the TB becomes bent), and coalescence of twins (or vanishing of twin boundaries) to continue twin growth [42]. Multiple twinning with parallel TBs divide the parent grains into twin/matrix lamellae. The mechanism of twinning growth consists of lamellae thickening of twins and inserting of new twin lamellae [43]. The mechanism of $\{332\}<113>$ twinning formation is not clarified today [22], and thus several models of $\{332\}<113>$ twinning were proposed. Among the models, the first crystallographic model corresponded to simple shears on successive twinning planes along the twinning direction, and thus it accompanied necessary shuffles for the other atoms [22] and is referred to as the shear-shuffling model [18]. Furthermore, the Hall-Petch-type relation may be applied to $\{332\}<113>$ twinning since $\{332\}<113>$ twinning obeys Schmid's law [18,19]. Wang et al. [18] reported that the Hall-Petch slope for $\{332\}<113>$ twinning $\beta$ Ti-20V-2Nb-2Zr alloy in stress-strain curve exceeds that of a governed dislocation glide when $\{332\}<113>$ mechanical twinning is dominant.

The next mission was elucidating the relationship between variants of $\{332\}<113>$ twining and deformation energy consumed to form $\{332\}<113>$ twins by using the shear-shuffle mechanism and subsequently clarifies the mechanism of $\{332\}<113>$ deformation twinning. The deformation is estimated as follows.

We calculate the elastic modulus and shear modulus with respect to the $\{332\}$ plane by using the results obtained by Wang et al. [1] given the paucity of studies that examine the $\{332\}$ plane. Based on the equations reported by Wang et al. [1] and given the anisotropy of materials, the values of the elastic constant and shear modulus correspond to $E_{\{332\}}=-0.126 \mathrm{GPa}$ and $G_{\{332\}}=0.063 \mathrm{GPa}$, respectively. Additionally, the results correspond to anomalous data when compared with results obtained by Tane et al. [44]. Given the isotropy of materials, the shear modulus and elastic modulus correspond to $G_{\{332\}}=29.6 \mathrm{GPa}$ and $E_{\{332\}}=0.18 \mathrm{GPa}$, respectively, and the results are consistent with those obtained in previous studies [44,45]. Given the low shear modulus on $\{332\}$ plane, we used the shear-shuffle mechanism for $\{332\}<113>$ twinning (Kawabata et al. [12] model) to calculate the deformation. In order to eliminate the interaction of the friction forces in the sample surfaces, we used Figure $2 b, c$.

We assumed that the simple shear-shuffle model is applicable to $\{332\}$ twinning, and thus the twinning energy corresponds to $W=\left.\tau s\right|_{\text {twin frame }}=\sigma_{\mathrm{y}} \varepsilon_{33}^{\prime} \mid$ crystal frame where $\tau$ denotes the critical resolved shear stress, $s$ denotes the twinning shear magnitude [30], $\sigma_{\mathrm{y}}$ denotes the yield strength, and $\varepsilon_{33}^{\prime}$ denotes the twinning deformation along ND direction (parallel to 3 axis) shown in Figure 1. Thus, the twinning normal of the plane corresponds to $\{332\}$ and the shear direction corresponds to $<113>$ such that the magnitude of the Burgers vector is $1 / 22<113>$ [12]. Wang et al. [30] used the Hall-Petch-type relation to clarify the variants of twins in titanium alloys with hexagonal close-packed (hcp) structure. The twin deformation energy is expressed as follows [30]:

$$
W=\tau s=\sigma_{0} \varepsilon_{33}^{\prime}+\frac{k}{\sqrt{L}} \varepsilon_{33}^{\prime}
$$


where, $W$ denotes the twin deformation energy that is considered as internal energy in the propagation stage, and $\sigma_{0}$ and $k$ are constant and viewed as theoretical yield stress. Additionally, $\varepsilon_{33}^{\prime}$ denotes the contribution of twinning deformation for macro-strain tensor component $\varepsilon_{33}$ applied along the 3 axis (the ND direction) in Figure 1. Furthermore, $L$ denotes the free path of the twin lamella prior to encountering an obstacle (grain boundary, precipitate or other twins) and is visualized with its longest boundary traces on the sample observation plane by means of stereographic [30] that determines the orientation of twinning variants by using the trace method [46,47] and is illustrated in Figure 3a. Thus, the results indicate that $L=35.7 \mu \mathrm{m}$ in grain G2-1. We assume that the alloy exhibits elastic isotropy, and thus $\varepsilon_{33}^{\prime} / \sqrt{L}$ dominates the magnitude of twinning deformation energy [30].
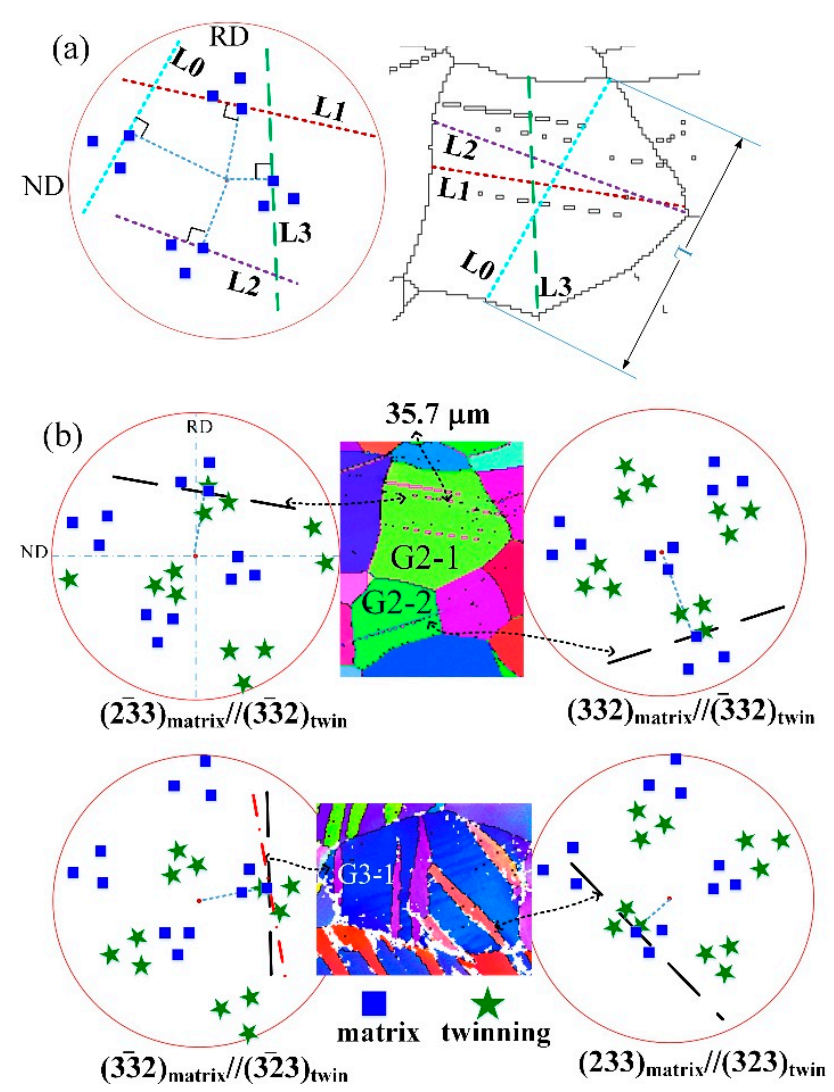

Figure 3. Schematic illustration of measuring the length of $L$ and identifying the variants of $\{332\}$ twinning (a) measuring the length of $L ;(\mathbf{b})$ identifying the variants of twinning.

The twinning strain tensor $\varepsilon_{i j}^{\prime \prime}$ in the orthonormal crystal sample coordinate system is expressed as follows [40]:

$$
\varepsilon_{i j}^{\prime \prime}=\gamma\left(\begin{array}{ccc}
b_{1} n_{1} & \frac{1}{2}\left(b_{1} n_{2}+b_{2} n_{1}\right) & \frac{1}{2}\left(b_{1} n_{3}+b_{3} n_{1}\right) \\
\frac{1}{2}\left(b_{2} n_{1}+b_{1} n_{2}\right) & b_{2} n_{2} & \frac{1}{2}\left(b_{2} n_{3}+b_{3} n_{2}\right) \\
\frac{1}{2}\left(b_{3} n_{1}+b_{1} n_{3}\right) & \frac{1}{2}\left(b_{3} n_{2}+b_{2} n_{3}\right) & b_{3} n_{3}
\end{array}\right)
$$

where, $\gamma$ denotes the magnitude of the twinning shear, here $\gamma \approx 0.0448[12,14],\left[n_{1}, n_{2}, n_{3}\right]$ denotes the normal to the twinning plane, and $\left[b_{1}, b_{2}, b_{3}\right]$ denotes the twinning direction in the crystal coordinate system. 
We assume that $G$ corresponds to the coordinate transformation matrix from the macroscopic sample coordinate system to the orthonormal twin reference system, and thus the strain tensor of twinning the sample coordinate system is expressed as follows [30]:

$$
\varepsilon_{i j}^{\prime}=G\left(\varepsilon_{i j}^{\prime \prime}\right) G^{-1}
$$

The variants of \{332\} twins inside grains G2-1, G2-2, and G3-1 (as shown in Figure 2) are identified by using the traces method [48] as shown in Figure 3b. Inside grain G2-1, the twins variant corresponds to the $(\overline{2} 33)_{\text {matrix }} / /(3 \overline{3} 2)_{\text {twin }}$, and G2-2 corresponds to the $(332)_{\text {matrix }} / /(\overline{3} 32)_{\text {twin }}$. Conversely, inside G3-1, there are two types of $\{332\}$ twins, and the variants correspond to the $(\overline{3} 32)_{\text {matrix }} / /(3 \overline{2} 3)_{\text {twin }}$ and (323) $)_{\text {matrix }} / /(233)_{\text {twin }}$.

Considering that effects of both $\omega$ and $\alpha^{\prime \prime}$ phase [9,22,24] on the model of Kawabata [12], the constant $k$ in Equation (1) is estimated by using the "partial dislocation model" for the nanocrystalline and nanotwinned metals [49,50], and then $k$ is expressed as follows:

$$
k=\frac{G b(4 \pi-1)}{24 \sqrt{L}}
$$

where, $b$ denotes the magnitude of $\{332\}<113>$ twinning dislocation with $b=1 / 22[113] a_{0} \approx 0.4954 \mathrm{~nm}$ and lattice constants $a_{0} \approx 0.3286 \mathrm{~nm}$ [51]. Furthermore, $G \approx 29.6 \mathrm{GPa}$ as mentioned previously [52].

Given that the behavior is sensitive to the chemical composition of Ti-Nb-based alloys [53], the constant $\sigma_{0}$ is estimated as $0.68 \mathrm{GPa}$ since its chemical composition is extremely similar to that in the results obtained by Withey et al. [5,7]. Nevertheless, the real value of $\sigma_{0}$ is less than 0.68 GPa since 0.68 GPa denotes the external load obtained in Withey et al. [5,7].

The deformation energy $W_{\text {twin }}$ for many grains in Figure 2 is calculated based on Equations (1)-(4), and the results for grains G2-1. G2-2 and G3-1 are listed in Table 1.

\begin{tabular}{|c|c|c|c|}
\hline \multirow{3}{*}{ Variant of $\{332\}$ Twins } & \multicolumn{3}{|c|}{ Deformation Energy, $\mathrm{J} / \mathrm{m}^{2} \times 10^{5}$} \\
\hline & \multicolumn{3}{|c|}{ Orientation of Grains } \\
\hline & G2-1 & G2-2 & G3-1 \\
\hline Euler Angle, ${ }^{\circ}$ & $(254.0,19.0,45.0)$ & $(202.3,50.0,45.6)$ & $(319.7,37.4,16.8)$ \\
\hline$(23 \overline{3})[3 \overline{1} 1]$ & -1.87 & 2.4 & -15.7 \\
\hline$(\overline{2} 33)[311]$ & $2.54 *$ & 15.4 & 17.2 \\
\hline (323) $[1 \overline{3} 1]$ & 5.33 & -26.6 & $-11.7 *$ \\
\hline$(3 \overline{2} 3)[131]$ & 10.9 & -6.86 & 14.1 \\
\hline$(3 \overline{3} 2)[\overline{1} 13]$ & 15.7 & -35.7 & -5.11 \\
\hline$(2 \overline{3} 3)[31 \overline{1}]$ & -24.6 & 4.59 & -7.53 \\
\hline$(\overline{3} 23)[13 \overline{1}]$ & -27.6 & 35.8 & 58.0 \\
\hline$(332)[11 \overline{3}]$ & -26.5 & $-26.6^{*}$ & -39.2 \\
\hline$(233)[\overline{3} 11]$ & 34.6 & 54.2 & 48.1 \\
\hline$(32 \overline{3})[\overline{1} 31]$ & 38.8 & -27.9 & 2.21 \\
\hline$(33 \overline{2})[113]$ & 47.4 & -0.213 & 24.4 \\
\hline$(\overline{3} 32)[1 \overline{1} 3]$ & 53.4 & 27.3 & $51.6^{*}$ \\
\hline
\end{tabular}

Table 1. Results of the deformation energy for $\{332\}<113>$ twinning.

* represent the active twinning variants.

The experimentally observed active variants are denoted as "*" in Table 1. As shown in Table 1, the deformation energy of (233)[311] twinning variants in G2-1 corresponds to $2.54 \times 10^{5} \mathrm{~J} / \mathrm{m}^{2}$ and that of (332) [11 $\overline{3}]$ corresponds to $26.6 \times 10^{5} \mathrm{~J} / \mathrm{m}^{2}$ in grain G2-2 while those in grain G3-1 correspond to $11.7 \times 10^{5} \mathrm{~J} / \mathrm{m}^{2}$ and $51.6 \times 10^{5} \mathrm{~J} / \mathrm{m}^{2}$, respectively. Thus, it is concluded that the deformation energy for $\{332\}<113>$ twins in Ti- $35 \mathrm{Nb}-\mathrm{O}\left(\mathrm{wt} \%\right.$ ) can range from $2.54 \times 10^{5}$ to $51.6 \times 10^{5} \mathrm{~J} / \mathrm{m}^{2}$ roughly. 
Additionally, the results indicate that the deformation energy does not correspond to the variant selection criterion for $\{332\}<113>$ twinning in the $\beta$-type Ti-35Nb-2Ta-3Zr-O(wt \%) alloy.

Kochmann et al. [36] investigated the energetic threshold for the onset of twinning using continuum mechanics model. Although the values of deformation energy in [36] was less than our results of deformation energy, the method of calculation for deformation energy was similar to our method. The main reasons for the disagreement between the results obtained in extant studies [36,54] and the results obtained in the current study correspond to the constant $\sigma_{0}$ in Equation (1). Specifically, the critical resolved shear stress (CRSS) for nucleation, propagation, and growth is not constant. The value of CRSS in nucleation was initially significantly high. It then decreased and subsequently increased when the onset of propagation was minimum $[42,47,55]$. Thus, the work derived from CRSS in the onset of propagation can be viewed as the threshold, and the value can be approximately viewed as deformation energy.

The results in Table 1 correspond to the deformation energy for the single slip system of $\{332\}<113>$ twinning formation, and thus the active volume on the $\{332\}<113>$ twins should refer to the numbers of the active atomic layers [55,56]. Based on Equations (1)-(4), in grain G2-1, the contribution of the (233)[311] twinning strain in the crystal coordinate frame to sample coordinate frame is 0.000372 , and the driving stress for (233)[311] twinning is $0.683 \mathrm{GPa}$. Thus, the value of the driving stress indicates that the value of $\sigma_{0}$ in Equation (1) controls the estimation value of deformation energy, and thus the real value of deformation energy is less than the obtained result since the yield stress corresponds to the resultant force including more than five active slip systems. Despite the approximate estimation, the value is consistent with that obtained by Morris Jr. et al. [57].

The deformation energy in the study corresponds to the total deformation because the Kawabata model [12] contains the shuffle. Takesue et al. [58] and Kawabata et al. [12] reported the yield strength of a single crystal in Ti-36Nb-2Ta-3Zr- $0.3 \mathrm{O}$ ( $\mathrm{wt} \%$ ) along the $<110>$ direction as approximately $200 \mathrm{MPa}$, the corresponding strain as 0.005 , and the total deformation energy including elastic strain energy and plastic strain energy as approximately $5 \times 10^{5} \mathrm{~J} / \mathrm{m}^{2}$. This is in good agreement with the results obtained in the present study. Similarly, the results obtained by Talling et al. [6,53] approximately corresponded to $22.5 \times 10^{5} \mathrm{~J} / \mathrm{m}^{2}$ for Ti-36Nb-2Ta-3Zr-0.3O ( $\mathrm{wt} \%$ ) alloy subjected to solution treatment and quenching. The deformation energy as reported by Morris Jr et al. [57] approximately corresponded to $11.7 \mathrm{~J} / \mathrm{m}^{2}$ for in situ tensile testing along the $<110>$ direction when $\alpha^{\prime \prime}$ emerged, and thus the results are also in good agreement with our results. A detailed comparison between the results reported by Takesue et al. [58] (or Kawabata et al. [12]) and Morris et al. [57] indicated that the results obtained by Takesue et al. [58] and Kawabata et al. [12] did not exhibit the emergence of an $\alpha$ " phase during the entire tension test and the yield strength was significantly low (approximately $200 \mathrm{MPa}$ ). The results obtained by Morris et al. [57] indicated an evident yield characteristic prior to the emergence of the $\alpha$ " phase and the yield strength (approximately $800 \mathrm{MPa}$ ) was significantly high. Furthermore, Takesue et al. [58] and Kawasaki et al. [12] reported that the strain corresponding to yield was approximately 0.005, while Morris Jr. et al. [57] reported an approximate strain of 0.025. Hanada et al. [17] indicated that $<332><113>$ twinning can form under any compressive axis in $\beta$-type Ti- $36 \mathrm{Nb}$ or Ti-36Nb-0.3O (wt \%) alloys, and this indicated that $\{332\}<113>$ twinning could form under a load with a sufficient magnitude in any direction. Thus, it is supposed that $\{332\}<113>$ twinning forms when the yield point emerges in Takesue et al. [58], meanwhile $\{332\}<113>$ twinning can also form after the emergence of the $\alpha^{\prime \prime}$ phase in Morris et al. [57]. In the study, the difference in deformation energy indicated that there are two types of mechanisms of $\{332\}<113>$ twinning formation, namely the shear-shuffle mode for low values of deformation energy and another type that is formed inside the $\alpha$ " phase for high values of deformation energy. The details of the discussion based on Taylor-Bishop-Hill theory follow.

From the discussed reviews, it was seen that there were obvious differences between the deformation energy of "deformation bands" [58] and that of $\alpha$ " phase formation [57]. The speculation is as follows: Metastable $\beta$-type Ti-Nb-based alloys are prone to $\beta$ - $\alpha$ " phase transformation under loading conditions with slight deformation. The $\alpha^{\prime \prime}$ phase reverses to $\beta$ in the case of unloading, 
and some $\{332\}<113>$ twinning remains in the alloy [12,23,58]. Lai et al. [22] and Chen et al. [24] proposed that $\{332\}<113>$ twinning originates from the $\alpha^{\prime \prime}$ phase. Additionally, the $\alpha^{\prime \prime}$ phase corresponds to an orthorhombic structure with the space group Cmcm [22]. Elmay et al. [59] indicated that the $\beta$ to $\alpha^{\prime \prime}$ phase transformation accompanies a high change in the lattice parameters with decreases in both parameters $a$ and $c$. Simultaneously an increase in parameter $b$ is caused by tensile deformation. Bertrand et al. [60] revealed that $\{130\}<310\rangle_{\alpha^{\prime \prime}}$ twinning is easily observed in the full $\alpha^{\prime \prime}$ phase. Chen et al. [24] suggested that the orientation relationship $(1 \overline{3} 0)_{\alpha^{\prime \prime}} / /(332)_{\beta}$ exists in a gradual transition zone from $\alpha^{\prime \prime}$ to $\beta$ inside the $\{332\}$ twinning band. Furthermore, the $\alpha$ " phase inside the $\beta$ phase is induced by shuffling adjacent to $\{110\}_{\beta}$ planes in the $\langle 1 \overline{1} 0\rangle_{\beta}$ direction $[61,62]$. Therefore, it is speculated that the steps for the $\{332\}_{\beta}$ twinning mechanism are as follows: the first corresponds to the $\beta$ to $\alpha^{\prime \prime}$ phase transformation under loading, the second corresponds to the appearance of $\{130\}_{\alpha^{\prime \prime}}$ twinning under loading, and the third corresponds to $\{130\}_{\alpha^{\prime \prime}}$ twinning to $\{332\}_{\beta}$ twinning during unloading. Therefore, $\{332\}_{\beta}$ twinning can be attributed to the $\alpha^{\prime \prime}$ phase in theory. Additionally, the $\alpha^{\prime \prime}$-assisted model is considered as a combination of active slip systems.

As mentioned, the previous experimental results $[6,57,58]$ are adequately consistent with our calculation results. In order to interpret the phenomenon, it is inferred that $\{332\}<113>$ twinning is derived from both the shear-shuffle mechanism and $\alpha^{\prime \prime}$-assisted twinning mechanism. Specifically, the expression on the left side of the second equal sign in Equation (1) corresponds to the single active slip system while the expression on the right side of the last equal sign corresponds to the external load that can include more than five active slip systems in case of yield conditions. Based on Taylor-Bishop-Hill theory $[32,63,64]$, the $\{332\}<113>$ twinning with a lower value of deformation energy corresponds to the shear-shuffle model because an active single-slip system requires minimum work, while the relatively higher value of the $\alpha^{\prime \prime}$-assisted twinning mechanism requires more than five active slip systems, and the work corresponds to the maximum. This indicates that the deformation energy reported in other studies must exceed that obtained in the results of the present study. Thus, the formation mechanism for the variants of $\{332\}<113>$ twinning with low deformation energy corresponds to the shear-shuffle model and those with a high value correspond to the $\alpha^{\prime \prime}$-assisted model. Among all the models of $\{332\}<113>$ twinning formation, only Kawabata et al. [12] and $\alpha^{\prime \prime}$-assisted twinning models are adequately consistent with the results obtained in previous studies (such as Tane et al. [4,44], Kawabata et al. [12], Yao et al. [13], Hanada et al. [17], Talling et al. [53], Morris Jr [57], and Takesue [58]) via the analysis of deformation energy based on the Hall-Petch-type relation. Moreover, Bishop et al. [64] proposed that the sum of the absolute values of a physically possible set of shears producing a given strain is less than that of a set which is only geometrically possible, and the model of Kawabata et al. [12] is well consistent with it.

\section{Conclusions}

In summary, the crystal orientation of the cold rolling bite zone was obtained via EBSD in Ti-35Nb-2Ta-3Zr-O (wt \%) alloy. We calculated the deformation energy of $\{332\}<113>$ twinning in the propagation stage using experimental data from EBSD based on the Hall-Petch-type relation. The mechanism of $\{332\}<113>$ twinning formation was investigated based on deformation energy. The main results are summarized as follows: (1) Specifically, $\{332\}<113>$ twinning predominated the microstructure in the complete rolling bite zone; (2) the deformation energy of $\{332\}<113>$ twinning did not correspond to the variant selection criterion for $\{332\}<113>$ twinning using the shear-shuffle mechanism; and (3) a comparison of our results with the results of previous studies indicated that the $\{332\}<113>$ twinning was derived from the shear-shuffle mechanism and $\alpha^{\prime \prime}$-assisted twinning mechanism. Additionally, variants of $\{332\}<113>$ twinning with a lower value of deformation energy corresponded to the shear-shuffle model, while higher values corresponded to the $\alpha^{\prime \prime}$-assisted twinning model. This result may improve our understanding of the mechanism of $\{332\}<113>$ twinning formation further. 
Author Contributions: All authors made the equal contribution to this article.

Funding: This research was funded by National Key R\&D Program of China, grant number (No. 2017YFA0403804).

Acknowledgments: The authors would like to acknowledge the financial support from National Key R\&D Program of China (No. 2017YFA0403804).

Conflicts of Interest: The authors declare no conflict of interest.

\section{References}

1. Wang, X.; Zhang, L.; Guo, G.Z.; Jiang, Y.Y.; Tao, X.M.; Liu, L.B. Study of low-modulus biomedical $\beta$ Ti-Nb-Zr alloys based on single-crystal elastic constants modeling. J. Mech. Behav. Biomed. 2016, 62, 310-318. [CrossRef] [PubMed]

2. Nunes, A.R.V.; Borborema, S.; Araújo, L.S.; Dille, J.; Malet, L.; Almeida, L.H. Production, microstructure and mechanical properties of cold-rolled Ti-Nb-Mo-Zr alloys for orthopedic applications. J. Alloy Compd. 2018, 743, 141-145. [CrossRef]

3. Shin, S.; Zhu, C.; Vecchio, K.S. Observations on $\{332\}$ Twinning-induced Softening in Ti-Nb Gum Metal. Mater. Sci. Eng. A 2018, 724, 189-198. [CrossRef]

4. Tane, M.; Nakano, T.; Kuramoto, S.; Hara, M.; Niinomi, M.; Takesue, N.; Yano, T.; Nakajima, H. Low Young's modulus in Ti-Nb-Ta-Zr-O alloys: Cold working and oxygen effects. Acta Mater. 2011, 59, 6975-6988. [CrossRef]

5. Withey, E.A.; Minor, A.M.; Chrzan, D.C.; Morris, J.W., Jr.; Kuramoto, S. The deformation of gum metal through in situ compression of nanopillars. Acta Mater. 2010, 58, 2652-2665. [CrossRef]

6. Talling, R.J.; Dashwood, R.J.; Jackson, M.; Kuramoto, S.; Dye, D. Determination of (image) in Ti-36Nb-2Ta-3Zr-0.3O (wt. \%) (Gum metal). Scr. Mater. 2008, 59, 669-672. [CrossRef]

7. Withey, E.; Jin, M.; Minor, A.; Kuramoto, S.; Chrzan, D.C.; Morris, J.W. The deformation of "Gum Metal" in nanoindentation. Mater. Sci. Eng. A 2008, 493, 26-32. [CrossRef]

8. Hayama, A.O.F.; Lopes, J.F.S.C.; Silva, M.J.G.D.; Abreu, H.F.G.; Caram, R. Crystallography texture evolution in Ti-35Nb alloy deformation by cold rolling. Mater. Des. 2014, 60, 653-660. [CrossRef]

9. Yang, Y.; Li, G.P.; Cheng, G.M.; Li, Y.L.; Yang, K. Multiple deformation mechanisms of Ti-22.4Nb-0.73Ta2.0Zr-1.34O alloy. Appl. Phys. Lett. 2009, 94, 61901. [CrossRef]

10. Zhao, G.H.; Ketov, S.V.; Jiang, J.; Mao, H.; Borgenstam, A.; Louzguine-Luzgin, D.V. New beta-type Ti-Fe-Sn-Nb alloys with superior mechanical strength. Mater. Sci. Eng. A 2017, 705, 348-351. [CrossRef]

11. Zhan, H.Y.; Zeng, W.D.; Wang, G.; Kent, D.; Dargusch, M. On the deformation mechanisms and strain rate sensitivity of a metastable $\beta$ Ti-Nb alloy. Scr. Mater. 2015, 107, 34-37. [CrossRef]

12. Kawabata, T.; Kawasaki, S.; Izumi, O. Mechanical properties of TiNbTa single crystals at cryogenic temperatures. Acta Mater. 1998, 46, 2705-2715. [CrossRef]

13. Yao, T.T.; Du, K.; Wang, H.L.; Huang, Z.Y.; Li, C.H.; Li, L.L.; Hao, Y.L.; Yang, R.; Ye, H.Q. In situ scanning and transmission electron microscopy investigation on plastic deformation in a metastable $\beta$ titanium alloy. Acta Mater. 2017, 133, 21-29. [CrossRef]

14. Zhou, X.Y.; Min, X.H.; Emura, S.; Tsuchiya, K. Accommodative $\{332\}<113>$ primary and secondary twinning in a slightly deformed $\beta$-type Ti-Mo titanium alloy. Mater. Sci. Eng. A 2017, 684, 456-465. [CrossRef]

15. Ji, X.; Emura, S.; Min, X.H.; Tsuchiya, K. Strain-rate effect on work-hardening behavior in $\beta$-type Ti-10Mo-1Fe alloy with TWIP effect. Mater. Sci. Eng. A 2017, 707, 701-707. [CrossRef]

16. Blackburn, M.J.; Feeny, J.A. Stress-induced transformations in Ti-Mo alloys. J. Inst. Met. 1971, 99, $132-134$.

17. Hanada, S.; Ozeki, M.; Izumi, O. Deformation Characteristics in $\beta$ Phase Ti-Nb Alloys. Metall. Trans. A 1985, 16, 789-795. [CrossRef]

18. Wang, W.L.; Wang, X.L.; Mei, W.; Sun, J. Role of grain size in tensile behavior in twinning-induced plasticity $\beta$ Ti-20V-2Nb-2Zr alloy. Mater. Charact. 2016, 120, 263-267. [CrossRef]

19. Min, X.H.; Emura, S.; Chen, X.J.; Zhou, X.Y.; Tsuzaki, K.; Tsuchiya, K. Deformation microstructural evolution and strain hardening of differently oriented grains in twinning-induced plasticity $\beta$ titanium alloy. Mater. Sci. Eng. A 2016, 659, 1-11. [CrossRef]

20. Crocker, A.G. Twinned martensite. Acta Metall. 1962, 10, 113-122. [CrossRef] 
21. Rusakov, G.M.; Litvinov, A.V.; Litvinov, V.S. Deformation twinning of titanium $\beta$-alloys of transition class. Met. Sci. Heat Treat. 2006, 48, 244-251. [CrossRef]

22. Lai, M.J.C.; Tasan, C.; Raabe, D. On the mechanism of $\{332\}$ twinning in metastable $\beta$ titanium alloys. Acta Mater. 2016, 111, 173-186. [CrossRef]

23. Obbard, E.G.; Hao, Y.L.; Talling, R.J.; Li, S.J.; Zhang, Y.W.; Dye, D.; Yang, R. The effect of oxygen on $\alpha^{\prime \prime}$ martensite and superelasticity in Ti-24Nb-4Zr-8Sn. Acta Mater. 2011, 59, 112-125. [CrossRef]

24. Chen, B.; Sun, W. Transitional structure of $\{332\}<113>_{\beta}$ twin boundary in a deformed metastable $\beta$-type Ti-Nb-based alloy, revealed by atomic resolution electron microscopy. Scr. Mater. 2018, 150, 115-119. [CrossRef]

25. Zhang, X.B.; Wang, W.L.; Sun, J. Formation of $\{332\}<113>_{\beta}$ twins from parent $\{130\}<310>_{\alpha}$ " plastic twins in a full $\alpha^{\prime \prime}$ Ti-Nb alloy by annealing. Mater. Charact. 2018, 145, 724-729. [CrossRef]

26. Tobe, H.; Kim, H.Y.; Inamura, T.; Hosoda, H.; Miyazaki, S. Origin of \{332\} twinning in metastable $\beta$-Ti alloys. Acta Mater. 2014, 64, 345-355. [CrossRef]

27. Wang, Y.Y.; Sun, X.; Wang, Y.D.; Hu, X.H.; Zbib, H.M. A mechanism-based model for deformation twinning in polycrystalline FCC steel. Mater. Sci. Eng. A 2014, 607, 206-218. [CrossRef]

28. Chen, J.S.; Zhou, X.B.; Chen, J. Sheet metal forming limit prediction based on plastic deformation energy. J. Mater. Process. Technol. 2010, 210, 315-322. [CrossRef]

29. Yang, M.; Dong, X.H.; Zhou, R.; Cao, J. Crystal plasticity-based forming limit prediction for FCC materials under non-proportional strain-path. Mater. Sci. Eng. A 2010, 527, 6607-6613. [CrossRef]

30. Wang, S.; Schuman, C.; Bao, L.; Lecomte, J.S.; Zhang, Y.; Raulot, J.M.; Philippe, M.J.; Zhao, X.; Esling, C. Variant selection criterion for twin variants in titanium alloys deformed by rolling. Acta Mater. 2012, 60, 3912-3919. [CrossRef]

31. Hu, X.H.; Houtte, P.V.; Liebeherr, M.; Walentek, A.; Seefeldt, M.; Vandekinderen, H. Modeling work hardening of pearlitic steels by phenomenological and Taylor-type micromechanical models. Acta Mater. 2006, 54, 1029-1040. [CrossRef]

32. Houtte, P.V. A Comprehensive mathematical mormulation of an mxtended Taylor-Bishop-Hill Model featuring relaxed constraints, the Renouard-Wintenberger theory and a strain rate sensitivity model. Textures Microstruct. 1988, 8, 313-350. [CrossRef]

33. Ma, B.; Liu, Z.G.; Jiang, Z.; Wu, X.; Diao, K.; Wan, M. Prediction of forming limit in DP590 steel sheet forming: An extended fracture criterion. Mater. Des. 2016, 96, 401-408. [CrossRef]

34. Wang, Y.M.; Tong, J.; Ma, E. Dynamic processes for nanostructure development in $\mathrm{Cu}$ after severe cryogenic rolling deformation. Mater Trans. 2003, 44, 1926-1934. [CrossRef]

35. Lee, S.; Im, J.; Yoo, Y.; Bitzek, E.; LKiener, D.; Richter, G.; Kim, B.; Oh, S.H. Reversible cyclic deformation mechanism of gold nanowires by twinning-detwinning transition evidenced from in situ TEM. Nat Commun. 2014, 5, 1-10. [CrossRef] [PubMed]

36. Kochmann, D.M.; Le, K.C. A continuum model for initiation and evolution of deformation twinning. J. Mech. Phys. Solids. 2009, 57, 987-1002. [CrossRef]

37. Yang, H.P.; Sha, Y.H.; Zhang, F.; Zuo, L. Through-thickness shear strain control in cold rolled silicon steel by the coupling effect of roll gap geometry and friction. J. Mater. Process. Technol. 2010, 210, 1545-1550. [CrossRef]

38. Slomchack, G.D.; Milenin, A.A.; Mamuzid, I.; Vodopivecm, F. A mathematical model of the formation of the plastic deformation zone in the rolling of rheologically complex metals and alloys. J. Mater. Process. Technol. 1996, 58, 184-188. [CrossRef]

39. Quagliato, L.; Berti, G.A. Temperature estimation and slip-line force analytical models for the estimation of the radial forming force in the RARR process of flat rings. Int. J. Mech. Sci. 2017, 123, 311-323. [CrossRef]

40. Niewczas, M. Lattice correspondence during twinning in hexagonal close-packed crystals. Acta Mater. 2010, 58, 5848-5857. [CrossRef]

41. Kumar, A.M.; Kanjarla, A.K.; Niezgoda, S.R.; Lebensohn, R.A.; Tomé, C.N. Numerical study of the stress state of a deformation twin in magnesium. Acta Mater. 2015, 84, 349-358. [CrossRef]

42. Sarker, D.; Friedman, J.; Chen, D.L. Twin growth and texture evolution in an extruded AM30 magnesium alloy during compression. J. Mater. Sci. Technol. 2014, 30, 884-887. [CrossRef]

43. Xiao, G.H.; Tao, N.R.; Lu, K. Effects of strain, strain rate and temperature on deformation twinning in a Cu-Zn alloy. Scr. Mater. 2008, 59, 975-978. [CrossRef] 
44. Tane, M.; Hagihara, K.; Ueda, M.; Nakano, T.; Okuda, Y. Elastic-modulus enhancement during room-temperature aging and its suppression in metastable Ti-Nb-Based alloys with low body-centered cubic phase stability. Acta Mater. 2016, 102, 373-384. [CrossRef]

45. Chaves, J.M.; Florêncio, O.; Silva, P.S.; Marques, P.W.B.; Afonso, C.R.M. Influence of phase transformations on dynamical elastic modulus and anelasticity of beta Ti-Nb-Fe alloys for biomedical applications. J. Mech. Behav. Biomed. 2015, 46, 184-196. [CrossRef] [PubMed]

46. Yu, H.H.; Li, C.Z.; Xin, Y.C.; Chapuis, A.; Huang, X.X.; Liu, Q. The mechanism for the high dependence of the Hall-Petch slope for twinning/slip on texture in Mg alloys. Acta Mater. 2017, 128, 313-326. [CrossRef]

47. Zhou, P.; Xiao, D.; Wang, W.Y.; Sang, G.; Zhao, Y.W.; Zou, D.L.; He, L.F. Twinning behavior of polycrystalline alpha-uranium under quasi static compression. J. Nucl. Mater. 2016, 478, 83-90. [CrossRef]

48. Shi, Z.Z.; Wagner, Y.D.; Zhang, F.; ReJuan, P.A.; Berbenni, S.; Capolungo, L.; Lecomte, J.S.; Richeton, T. On the selection of extension twin variants with low Schmid factors in a deformed Mg alloy. Acta Mater. 2015, 83, 17-28. [CrossRef]

49. Gu, P.; Kad, B.K.; Dao, M. A modified model for deformation via partial dislocations and stacking faults at the nanoscale. Scr. Mater. 2010, 62, 361-364. [CrossRef]

50. Gu, P.; Dao, M.; Asaro, R.J.; Suresh, S. A unified mechanistic model for size-dependent deformation in nanocrystalline and nanotwinned metals. Acta Mater. 2011, 59, 6861-6868. [CrossRef]

51. Lazar, P.; Jahnátek, M.; Hafner, J.; Nagasako, N.; Asahai, R.; Schenner, C.B.; Stöhr, M.; Podloucky, R. Temperature-induced martensitic phase transitions in gum-metal approximants: First-principles investigations for $\mathrm{Ti}_{3} \mathrm{Nb}$. Phys. Rev. B 2011, 84, 54201-54202. [CrossRef]

52. Zhang, Y.W.; Li, S.J.; Obbard, E.G.; Wang, H.; Wang, S.C.; Hao, Y.L.; Yang, R. Elastic properties of Ti-24Nb4Zr-8Sn single crystals with bcc crystal structure. Acta Mater. 2011, 59, 3081-3090. [CrossRef]

53. Talling, R.J.; Dashwood, R.J.; Jackson, M.; Dye, D. Compositional variability in gum metal. Scr. Mater. 2009, 60, 1000-1003. [CrossRef]

54. Le, K.C.; Sembiring, P. Plane constrained shear of single crystal strip with two active slip systems. J. Mech. Phys. Solids. 2008, 56, 2541-2554. [CrossRef]

55. Lagerlöf, K.P.D.; Castaing, J.; Pirouz, P.; Heuer, A.H. Nucleation and growth of deformation twins: A perspective based on the double-cross-slip mechanism of deformation twinning. Philos. Mag. A 2002, 82, 2841-2854. [CrossRef]

56. Ovid, K.I. Nanoscale multiplane shear and twin deformation in nanowires and nanocrystalline solids. Appl. Phys. Lett. 2011, 99, 061907. [CrossRef]

57. Morris, J.W., Jr.; Hanlumyuang, Y.; Sherburne, M.; Withey, E.; Chrzan, D.C.; Kuramoto, S.; Hayashi, Y.; Hara, M. Anomalous transformation-induced deformation in $<110>$ textured Gum Metal. Acta Mater. 2010, 58, 3271-3280. [CrossRef]

58. Takesue, N.; Shimizu, Y.; Yano, T.; Hara, M.; Kuramoto, S. Single-crystal growth of Ti-Nb-Ta-Zr-O alloys and measurement of elastic properties. J. Cryst. Growth. 2009, 311, 3319-3324. [CrossRef]

59. Elmay, W.; Berveiller, S.; Patoor, E.; Gloriant, T.; Prima, F.; Laheurte, P. Texture evolution of orthorhombic $\alpha^{\prime \prime}$ titanium alloy investigated by in situ X-ray diffraction. Mater. Sci. Eng. A 2017, 679, 504-510. [CrossRef]

60. Bertrand, E.; Castany, P.; Yang, Y.; Menou, E.; Gloriant, T. Deformation twinning in the full- $\alpha$ " martensitic Ti-25Ta-20Nb shape memory alloy. Acta Mater. 2016, 105, 94-103. [CrossRef]

61. Tahara, M.; Kim, H.Y.; Inamura, T.; Hosoda, H.; Miyazaki, S. Lattice modulation and superelasticity in oxygen-added $\beta$-Ti alloys. Acta Mater. 2011, 59, 6208-6218. [CrossRef]

62. Wang, X.L.; Li, L.; Xing, H.; Ou, P.; Sun, J. Role of oxygen in stress-induced $\omega$ phase transformation and $\{332\}<113>$ mechanical twinning in $\beta$ Ti-20V alloy. Scr. Mater. 2015, 96, 37-40. [CrossRef]

63. Hill, R. A variational principle of maximum plastic work in classical plasticity. Q. J. Mech. Appl. Math. 1948, 1, 18-28. [CrossRef]

64. Bishop, J.F.W.; Hill, R. A theory of the plastic distortion of a polycrystalline aggregate under combined stresses. Philos. Mag. 1951, 42, 414-427. [CrossRef]

(C) 2018 by the authors. Licensee MDPI, Basel, Switzerland. This article is an open access article distributed under the terms and conditions of the Creative Commons Attribution (CC BY) license (http:/ / creativecommons.org/licenses/by/4.0/). 